\title{
Yuval Noah Harari: una aproximación crítica
}

\author{
Mario Arroyo Martínez \\ Universidad Panamericana (México)
}

Yuval Noah Harari nos ofrece, en dos libros publicados en los últimos años, ${ }^{1}$ una interesante y original visión de la historia humana en la que complementa, sugestivamente, la tradicional información de carácter histórico, con otra de carácter biológico y científico en general. El resultado es una interesante obra de carácter interdisciplinar, aderezada con un ingenioso intercambio de información y un rico acervo de literatura científica, en gran medida tomada de recientes artículos publicados en revistas especializadas. Nos ofrece así una apretada y panorámica visión de la historia humana desde el despuntar del homo sapiens hasta la actualidad, con algunas a la par sugerentes e inquietantes reflexiones sobre el futuro y supuestamente probable fin de la especie humana. No en vano ha constituido un auténtico fenómeno editorial, que ha colocado en los primeros lugares de ventas un texto con un claro contenido cultural.

Ahora bien, todo ese novedoso despliegue sigue también la particular y original visión de la historia propia del autor o, dicho de otra forma, contiene una visión filosófica de la realidad inconfesada que el autor presupone. La información por él recopilada está orientada a respaldar su postura ideológica, silenciando, por contrapartida, lo que no contribuye a pintar la realidad como él la muestra. La perspectiva de la que parte es hábilmente disimulada a través de una cuidada redacción, aderezada con informaciones en extremo interesantes, que por momentos vuelven deliciosa la lectura del texto.

Los ingredientes que le permiten ofrecer esa interesante visión son cuestionables, es decir, si bien el trabado final de su postura es consistente, los elementos que utiliza para elaborarla no lo son tanto. Como es sabido, la lógica clásica enseña que de una premisa falsa se puede seguir cualquier cosa. ${ }^{2}$ Harari construye su original visión con una serie de ingredientes que no prueba y da por supuestos, y siendo, si no claramente falsos por lo menos problemáticos o cuestionables, todo lo que construya a partir de ahí tendrá ese 'pecado original'

1 De animales a dioses. Breve historia de la humanidad. México, Debate, 2016 y Homo deus. Breve historia del mañana. México, Debate, 2018. Al citar ambos textos se abreviarán los títulos: De animales a dioses se cita como AD y Homo deus como HD.

2 Cfr. Aristóteles, Analíticos primeros, II, 3. 55b2-56b3. 
o defecto estructural que permite dudar de la solidez del planteamiento. Su postura, si bien muy original e interesante, terminaría por ser falsa o errónea si lo son sus presupuestos inconfesados. Su filosofía implícita adquiere así un marcado tinte ideológico, por obviar lo que en realidad debería demostrar si quisiera ser plenamente consistente. Encarnaría bastante acabadamente lo que Platón llama un "verdadero sofista", ${ }^{3}$ es decir, una persona que con gran erudición y habilidad enseña finalmente doctrinas erróneas, e induce a muchas personas a la confusión.

¿Cuáles serían las premisas que el autor presupone y no demuestra?, ¿cuáles las cosas que calla para acomodar la realidad a su esquema predeterminado? Principalmente el materialismo, que da por supuesto. La idea de que solo y necesariamente somos materia, y no puede ser de otra manera. Particularmente en su versión biológica: la biología y, dentro de ella, la evolución, serían las claves para comprender todo desarrollo humano. En este sentido, puede sentarse una prioridad de la biología respecto de la historia, lo que viene a ser a un tiempo su mérito y su límite.

Unido a ello va el cientificismo, es decir, la doctrina que considera como única aproximación legítima hacia la realidad la propia de la ciencia. Cientificismo que se asume con un carácter dogmático, apenas disimulado, pues utiliza con frecuencia expresiones como "en el dogma científico actual" ${ }^{4}$ o la "ortodoxia científica". ${ }^{5}$ Cuando, en realidad, la ciencia no funciona con dogmas ni ortodoxias.

Con frecuencia da por científicamente demostrados teorías o ensayos científicos que tienen un carácter preliminar o no son patrimonio común de toda la comunidad científica, pero que son elegidos selectivamente porque comparten su visión materialista de fondo, que pretende mostrar como oficial o canónica. Tales serían, por ejemplo, su respaldo acrítico a la memética" de Dawkins ${ }^{6}$-no compartida por la mayoría de los biólogos-, o la visión del "intérprete cerebral" de Gazzaniga, ${ }^{7}$ que es una hipótesis neurocientífica cuestionable. Otras veces saca conclusiones de experimentos científicos que no sostenían necesariamente quiénes los realizaron, siendo entonces su postura una interpretación de la ciencia más que un frío dato objetivo. Tal es el caso de las consecuencias que extrae de los experimentos tipo Libet para dar por finiquitada la noción de ‘libertad'. ${ }^{8}$ El mismo Benjamín Libet no lo consideró así, y sostuvo en cambio que la libertad del hombre se manifestaba como una "capacidad de veto".

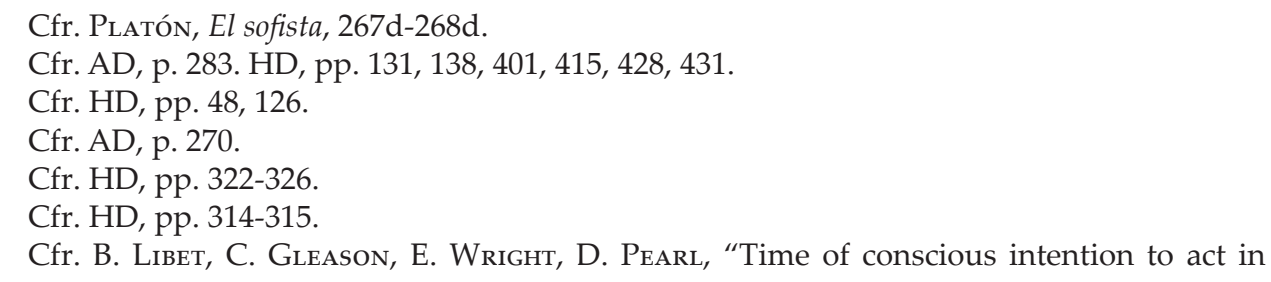


Su estilo no es polémico, no busca el debate, la confrontación o el ataque. Es más elegante, y con una fina ironía muestra como ingenuos, cuando no tontos o ignorantes, a quienes no comparten sus presupuestos de partida. Por eso mismo, muchas veces su lenguaje adquiere un marcado tinte 'oracular', como revelación de una verdad que había estado oculta a los ojos de la humanidad, hasta que llegó él a quitarnos la venda. Pero esos presupuestos implican, necesariamente, simplificar mucho las realidades descritas para que así quepan en su esquema explicativo. Así, por ejemplo, su división de la realidad en "objetiva, subjetiva e intersubjetiva" 10 es interesante a la par que reductiva. Pero, una vez aceptada, no hay forma de dar consistencia al derecho, la ley, la religión, la dignidad humana. Todos serían ficciones útiles de nuestra imaginación, necesarias para conseguir la colaboración de un gran número de sapiens. ${ }^{11}$

Con este esquema explica, muy originalmente, el papel que el dinero, los imperios y las religiones han tenido en plasmar el mundo como es actualmente. ${ }^{12}$ Su análisis resulta en extremo interesante, pero uno debe ser consciente de que ese engranaje maravilloso es posible por la simplificación que realiza de los elementos en discusión.

Su recepción acrítica de algunos resultados científicos o, mejor dicho, de determinadas interpretaciones de esos resultados, lo lleva a conclusiones curiosas y, bien mirado, contradictorias. Por ejemplo, la negación de que exista algo como 'los individuos', 'los sujetos' o 'las personas' (HD, p. 121), pues el 'yo' sería una ficción creada por nuestro cerebro. La conclusión inmediata sería también la 'ilusión' de la libertad..$^{13}$ Ya no hay espacio para una realidad 'libre', la cual sería también creación de "nuestra imaginación". Ahora bien, eso convierte también a su teoría en "creación de nuestra imaginación", y no está muy claro a quién o a qué nos referimos con el término 'nuestra', dado que no existe algo como el 'yo' (y, por tanto, 'nosotros') siendo, esto último, creación del cerebro.

Es decir, ¿estaba biológicamente determinado que él -la ficción que su cerebro crea y que denominamos Juval Noah Harari- escribiera el libro, nos abriera los ojos para enseñarnos que "no existimos", no somos libres y todo lo que no es biológica o físicamente demostrable es fruto de nuestra -no sabiendo muy bien a quién o a qué nos referimos con la expresión "nuestra"- imaginación? En síntesis, vuelve a caer en la falacia conceptual en la que reiterativamente incurren el positivismo, el neopositivismo y el nuevo ateísmo: establecer acientíficamente que solo es válido el conocimiento científico. Dicho más simplemente, la libertad

relation to onset of cerebral activity (readiness potential). The unconscious initiation of a freely voluntary act", Brain (1983), n. ${ }^{\circ} 106$, p. 641.

10 Cfr. HD, p. 165. AD, p. 135.

11 Cfr. AD, pp. 41, 51-53, 127, 129, 132-137.

12 Cfr. AD, pp. 194-195.

13 Cfr. HD, pp. 312, 334-335. 
y la individualidad, teóricamente negadas, vuelven a entrar subrepticiamente, una y otra vez, por la puerta de atrás. Se dan sencillamente como supuestas.

Una y otra vez justifica en la ciencia afirmaciones que, por supuesto, van mucho más allá de lo que la ciencia pueda en ningún caso revelar, ya sea ahora o en el futuro, como cuando afirma categóricamente, como si de una evidencia científica se tratara:

Hasta donde podemos saber, desde un punto de vista puramente científico, la vida humana no tiene en absoluto ningún sentido. Los humanos son el resultado de procesos evolutivos ciegos que operan sin objetivo ni propósito. Nuestras acciones no forman parte de ningún plan cósmico divino. $(A D, p$. $428){ }^{14}$

¿Qué experimento o ecuación matemática puede concluir que la vida no tiene sentido y que no hay un plan cósmico divino? Si no puedo demostrar científicamente que Dios no existe, ¿cómo puedo saber que no hay plan cósmico divino? ¿No será, en cambio, que la ciencia no es la herramienta adecuada para descubrir el sentido del universo y de nuestra vida? La premisa escondida en su tajante afirmación es: "la evolución nos proporciona la única clave de comprensión del universo" (AD, p. 429). El lugar que antaño ocupaba la metafísica ahora lo ocupa la teoría de la evolución, y no cualquier versión, sino exclusivamente la que está cerrada a cualquier forma de trascendencia (es decir, la versión de Richard Dawkins), y ahí no hay espacio para Dios. Harari no puede ignorar que algunos de los más grandes cultivadores y desarrolladores de la teoría evolutiva no están cerrados a la realidad religiosa o espiritual: Francisco J. Ayala, ${ }^{15}$ Stephen J. Gould, ${ }^{16}$ Theodosius Dobzhansky ${ }^{17}$ y jel mismo Charles Darwin al final de la primera edición de El origen de las especies! ${ }^{18}$ Tampoco que la misma teoría de la evolución ha evolucionado bastante en sus primeros 150 años de existencia.

Esa ignorancia selectiva lo lleva a incurrir en ocasiones en errores de bulto: "¿Qué descubrieron sacerdotes, rabinos y muftíes en el siglo XX que pueda mencionarse al mismo nivel que los antibióticos, los ordenadores o el feminismo?" (HD, p. 305), se pregunta. La respuesta que ignora: la teoría del Big Bang, sobre el origen del universo, fue formulada por el sacerdote católico Georges Lemaitre.

14 Cfr. también HD, pp. 119, 225-226, 248-249, 419.

15 Cfr. F. J. Ayala, La teoría de la evolución. De Darwin a los últimos avances de la genética. Madrid, Temas de Hoy, 1994, pp. 21-22.

16 Cfr. Stephen J. Gould, Ciencia vs. religión: un falso conflicto. Barcelona, Crítica, 2000.

17 Cfr. Michael Ruse, ¿Puede un darwinista ser cristiano? La relación entre ciencia y religión. Madrid, siglo XXI, 2007, p. 10.

18 Cfr. Charles Darwin, El origen de las especies. México, GET, 2005, p. 474. 
Otras veces parte axiomáticamente de afirmaciones gratuitas: "A la gente le hace feliz una cosa, y solo una: sensaciones agradables en su cuerpo" (HD, p. 48). Su punto de partida es un hedonismo materialista no plenamente justificado. Luego ofrece unas explicaciones lo más complicadas posibles, para encuadrar los contraejemplos que cuestionan ese estrecho esquema, por ejemplo al intentar mantenerlo y explicar simultáneamente el amor de las madres. ${ }^{19}$

En fin, a base de simplificar los problemas, puede reconducirlos a su sugestivo esquema, como al explicar que la vida son solo algoritmos y que, de esta forma, los algoritmos creados por nosotros pueden superar a los algoritmos naturales. La inteligencia artificial puede hacer los procedimientos mucho mejor que nosotros, y nos va a desplazar. No se olvide que ya antes ha llegado a la conclusión de que el 'yo', la 'persona' y la 'dignidad' no existen, o son solo creaciones imaginarias. No es extraño que, si las simplifica reduciéndolas a un 'algoritmo' (HD, p. 101), contemplándolas solo desde una perspectiva prácticoutilitarista, pueda afirmar después que las computadoras van a convertir en obsoletos a la gran mayoría de los humanos. ${ }^{20}$

Un cúmulo de suposiciones confluye para que pueda sostener con soltura su postura. Por ejemplo, obvia que al día de hoy no sabemos cómo se produjo la vida, simplemente suponemos cómo unas especies han cambiado para dar lugar a otras, y hemos sido incapaces tanto de definir con precisión ¿qué es la vida?, cómo producirla en laboratorio. Dadas todas estas incógnitas científicas, es pretencioso que finalmente diga, como si se tratara de una verdad evidente, que la vida es solo un 'algoritmo'.

La obra de Harari tiene entonces su límite en su atractivo. El ser una presentación armónica, interdisciplinar, y unitaria de la historia y la biología humanas desde un prisma exclusivamente materialista. Pero, al mismo tiempo, la visión materialista de la historia, para ser coherente, necesita simplificar un gran cúmulo de realidades humanas, quitar relevancia a nuestras actuales lagunas del conocimiento y hacer un acto de fe en futuros desarrollos científicos.

En ese sentido, por ejemplo, resulta curioso cómo reconoce con honestidad nuestra ignorancia sobre lo que es la conciencia, o cómo surgió, o para qué sirve, y pasa inmediatamente después a decir que los animales también tienen conciencia ${ }^{21} \mathrm{y}$, más adelante, a señalar que obviamente el cerebro lo es todo, no hay lugar para nociones como el 'alma' ${ }^{\prime 22} \mathrm{o}$ el ' $\mathrm{yo}^{\prime}{ }^{23}$

De hecho, bien mirado, esas afirmaciones son contradictorias. Pero se presentan como si no lo fueran. Por un lado, reconoce que no sabemos por qué

\footnotetext{
19 Cfr. HD, pp. 327-328.

20 Cfr. HD, pp. 117, 308, 337, 349.

21 Cfr. HD, p. 141.

22 Cfr. HD, pp. 119, 134.

23 Cfr. HD, pp. 121-122.
} 
un evento físico (un intercambio de energía -diferencial de potencial- a nivel neuronal) produce una experiencia consciente. No sabemos cómo surgió eso, no sabemos para qué sirve, qué ventaja evolutiva otorga, no se observa en ninguna otra realidad del universo. Más adelante se niega, sin embargo, que exista algo así como el 'yo'. La ciencia habría demostrado que el 'yo' es una ficción, así como la libertad. ${ }^{24}$ Ambas serían ficciones útiles creadas por el cerebro. Pero, entonces, ¿de quién es la experiencia consciente de la que no podemos dar razón?, ¿qué es esa experiencia consciente? Es decir, primero se afirma taxativamente que no sabemos por qué existe una realidad, o cómo se produce o por qué se produce. Páginas más adelante negamos que tal realidad exista.

Esa maniobra conceptual, auténtico malabarismo ideológico, es fruto de la premisa implícita, del dogma intangible que sirve como punto de partida de todo el planteamiento: el materialismo nihilista, que busca una justificación histórico-evolutiva.

Pero cabe también otra perspectiva. Es decir, los puntos oscuros de su línea argumentativa, las $\mathrm{x}$ sin despejar, lo que por el momento ignoramos, pero hacemos un acto de fe en que en el futuro podremos saber con claridad y aclarar todas las dudas; puede explicarse también de otra forma, aunque prohibida por la "ortodoxia materialista".

También es posible, por ejemplo, que esa "revolución cognitiva" (AD, p. 35), que hace 70000 años hizo de un frágil animal el amo del mundo se deba a que ese "animal" adquirió "conciencia de sí" por tener un nuevo principio de carácter espiritual, radicalmente diferente de los demás principios biológicos operantes en este mundo. ¿Por qué han fracasado todos los intentos por explicar cómo un determinado evento físico se convierte en una experiencia consciente? Quizá por buscar una explicación científica, y por ello exclusivamente material de una realidad que es de otro orden, que no es material sino espiritual, la conciencia que, necesitando del cerebro como órgano, no se reduce al mismo.

¿Por qué el hombre empezó a contar historias, crear ficciones, producir arte, plasmar religiones? Porque dejó de ser "solo biología" y comenzó a tener un componente espiritual. Ya no buscó exclusivamente lo que contribuye a su supervivencia o la "preservación de sus genes" (AD, p. 101), sino se interesó por lo que la realidad es en sí misma: primero el mundo y luego él mismo. Pero si eso es así, lo espiritual es tan real como lo material biológico. En ese caso, la religión y los derechos humanos dejarían de ser una "ficción útil" para producir cohesión social. El "humanismo" ya no sería una "religión" (HD, p. 249), sino el descubrimiento necesario de nuestra dignidad inherente.

Pero, en ese caso, se derrumban también los prejuicios animalistas de Harari, que constituyen un notable marketing a su doctrina, por dar fundamento teórico a un mainstream del pensamiento contemporáneo: la sensibilidad por

${ }^{24}$ Cfr. AD, p. 128. HD, pp. 312-314. 
los animales. Se le debe reconocer el gran interés que pone en mantenernos al tanto de los últimos descubrimientos en lo que a la vida, las emociones y al pensamiento animal se refiere; resultan una de las partes más enriquecedoras de sus textos. Pero el respeto a los animales no se construye necesariamente sobre la infravaloración de lo humano. No tenemos que abajarnos nosotros para valorarlos. Por ello ignora, también sistemáticamente, la contribución que el pensamiento religioso ha prestado a preservar la naturaleza, del Cántico de las criaturas de san Francisco de Asís a la carta encíclica Laudato sii del papa Francisco.

Para justificar su credo materialista, Harari debe restar importancia a las cosas que ignora la ciencia, interpretar de forma oportunista los resultados de algunas investigaciones y hacer un acto de fe en los futuros desarrollos científicos. Pero no es el único camino. Otros podemos sencillamente buscar una explicación no científica para algunos fenómenos, como la conciencia, el despuntar racional del hombre, la libertad y la dignidad humanas, que no por no comparecer en el laboratorio son menos reales. No se trata, ni siquiera, de hacer un acto de fe en "el Dios tapaagujeros" -que pudorosamente disimularía nuestra ignorancia- y en "el alma espiritual", sino sencillamente de no cerrarse dogmáticamente a un único canal del conocimiento humano, que sería el tecnológico-científico. ¿Es demostrable científicamente que solo lo científicamente demostrado merezca el nombre de conocimiento? No, como no es demostrable que Dios no exista. Pero ello, en vez de limitar nuestro conocimiento, lo estimula en otros ámbitos que, siendo diversos del científico, son también complementarios. Pero entonces no queda espacio para la negación a priori del espíritu, necesaria para justificar "científicamente" al materialismo.

La conclusión de Harari, cerrada a la trascendencia y al sentido, no puede sino ser nihilista y desesperanzadora. El futuro que presenta hace palidecer a las más conocidas distopías, desde Un mundo feliz, 1984 o Matrix a los que tiene en cuenta. ${ }^{25}$ En ese sentido, como los más grandes pensadores ateos al estilo Nietzsche, que son coherentes con sus premisas hasta las últimas consecuencias, saca con aguda lucidez y clarividencia las consecuencias de la ausencia de Dios, de sentido y de trascendencia, las cuales nos abocan, como proféticamente sugiere, a la desaparición del homo sapiens. No nos queda sino esperar que, como sus antecesores nihilistas, esté equivocado.

$25 \quad$ Cfr. AD, pp. 427, 152. HD, p. 423. 